\title{
THE CORNER: INNOVATIVE SERVICES
}

\author{
DAVID EPSTON
}

This issue highlights Horses For Hope, which operates in rural Victoria, Australia. The author is Colin Emonson, a thirty year veteran of youth, family, and community work in service, delivery management, and development. Horses for Hope combines his love of his horses and the hope he has for youth, families, and adults. He is currently studying on the year long Dulwich Centre Narrative Training Program in Adelaide.

\section{Horses For Hope}

This paper outlines the history and processes of combining Monty Roberts ${ }^{\circledR}$ Join $\mathrm{Up}{ }^{\circledR}$ method of nonviolent horse education and training (Roberts, 2002, 2008), and Narrative Practice to create Equine Assisted Narrative Practice. We began a collaboration with David Epston earlier this year to enhance the therapeutic components of our program.

At Horses For Hope, we have been developing the Equine Assisted Narrative Practice method for a number of years at Shepparton in rural Victoria, Australia. The program functions with three full-time staff and a volunteer available up to two days a week. Approximately 200 clients attend the program each year. The program operates from two locations in the region, one of which is in the Kinglake district which was devastated by bushfires in 2009 with the loss of 173 lives.

In short, the program uses troubled horses to engage and work with troubled people. It uses the Join $U p{ }^{\circledR}$ method of horse education and training, developed by Monty Roberts ${ }^{\circledR}$, combined with Narrative Therapy to engage people in a process of repositioning themselves against problems that in many cases have been all-encompassing and overpowering of them. Most, if not all, of these people have experienced significant trauma in their lives. By the same token, most troubled horses have suffered trauma at the hands of human beings and there is much in common between the troubled horse and the troubled person who has also suffered at the hands of others. Given the right encouragement, support, and training, there is an empathy and insightfulness that can naturally flow between the troubled horse and the troubled person. This can lead to a connection and understanding and a sense of pride in achievement when one (the person) is able to assist the other (the horse) in healing and recovery. Both the horse's and person's healing and recovery are given equal importance in this program. When a person enters the program, we 
establish an expectation that they will be engaged in "unsuffering the suffering" of horses" (Roberts, 2008). Often their agreement to undertake this is a unique event in the participant's life so far.

For this program to succeed, we require both highly developed horsepersonship and therapeutic skills. The program has given a lot of attention and resources to ensure that both these areas of need are adequately covered. Team member Tiffany Peverall is responsible for the horsepersonship component of the program. Tiffany's training is directed by Monty Roberts ${ }^{\circledR}$. It is worth noting that even though we are often working with horses who have a substantial level of fear regarding humans, no one has ever been injured in the years of operation of the program.

We believe that one of the reasons for the program's effectiveness is that so many of the principles that apply to working with people using Narrative Practices are exactly the same as those for working with horses using Monty Roberts ${ }^{\circledR}$ Join $\mathrm{Up}{ }^{\circledR}$ method. Everything that a participant does with a horse is a metaphor or an example for their own functioning and is available for use within narrative therapy practice. For example, people attending the program are often seeking behavioral changes which firstly require some capacity for emotional identification and regulation. Working with horses also requires emotional identification, regulation, and projection. David Epston introduced us to the idea of a person first needing to be able to "look at one's self through the eyes of another" in the process of establishing effective emotional regulation. In order to work well and safely with a horse, we are constantly asking participants to look at themselves through the eyes of the horse. We asked questions such as "what is it that the horse is feeling right now?" "what is the horse seeing in you right now?" If the horse is feeling unsafe, we might ask, "what might you show the horse from within yourself to enable her/him to feel safe?" By managing this relational process well, the horses feel safe and feel no need to flee, fight, or endanger the participant. With the right support and guidance, all participants are able to manage this process successfully and this leads to strong and sometimes an almost overwhelming emotional sense of person-horse connection and justifiable pride in having achieved this. For many, this is a unique experience, the therapeutic value of which should not be underestimated. These are also very powerful moments for significant others who are usually in attendance. Parents and carers who attend with young people are almost overwhelmed by the experience of watching their children achieve such things. Many are moved to tears and have used words like "in the horse yard I saw the child that I thought I had lost."

Recently a 12-year-old attended who has been diagnosed with an auditory learning disorder, oppositional defiant disorder and is currently being assessed for Asperger's. Due to the difficulties his behavior presents, he has only been allowed to attend school a few hours each week. He is also having considerable difficulties functioning within his family. Aggression and dominance have become the major means by which he related to everyone in his life. During his first session, surprisingly he demonstrated a phenomenal capacity to project a serene calmness towards his horse. Looking at himself "through the eyes of the horse," he consistently 
provided what the horse required to feel safe and connected with him. This was so different to how he related to others that his mother could not contain herself from crying throughout the session. When asked what the tears were saying, she replied that they were "tears of joy because I and the horse are seeing such wonderful things in my son." She added that she believed that the tears were also because "my son was rediscovering these things in himself."

So what might this experience mean for this lad? He didn't verbalize much; we didn't ask many questions, but he had a huge smile on his face and was very keen to return. We can be much more inquisitive about an experience as momentuous as this and engage in inquiry to enable the participant, regardless of age, to draw as much meaning from the experiences as possible. However it is not always appropriate to do so. This was one of those occasions when we allowed the experience of "join up" to speak for itself.

A common expression being used in Equine Assisted Therapy is that "horses hold a mirror to who we are" and we consider this to be a very accurate description of the reflections that horses provide of ourselves. Horses cannot lie and their survival over millions of years has depended on their capacity to interpret and reflect the emotions, feelings, and energy of predators. People are horses' most dangerous predators and they remain very well aware of this. Their survival over millions of years has depended upon this and these instincts are still very strong. What this horse reflected back to this young lad was a genuine sense of calm, safety, trustworthiness, and kindness. This was obvious to our Program Team, his mother as well as himself. This made him feel good about himself, and justifiably challenged many of the views of himself that he brought along to the program. The join up had instigated a challenge to his widely known reputation as "troubled" and/or "trouble." There was another important element to this story as well. Along with all these diagnosed problems, he was also considered to have a learning difficulty. However, he was able to take in and retain all the complex information that we teach people before they get into the yard. He was then able to use this information with no more instruction than any other person with a "good" learning capacity might expect. What had transpired? What we witnessed didn't seem to be in accord with what we had been told and what he seemed to think of himself in terms of his learning capacity. Not surprisingly we become interested in this and asked him if he had any views or ideas about it. Not surprisingly he was baffled by this and couldn't really think of any explanations. This was not something that we enquired strongly about; we basically just pointed out what has happened and our surprise at it happening and wondered out loud about it. Over the next three weeks prior to returning for his second session, his mother began receiving e-mails and phone calls from school seeking some explanation as to what had happened to him. He was being much more attentive; he was no longer getting into difficulties with either his classmates or teachers; he was not being aggressive and he had even managed to be awarded "a student of the week" award. This took him, his parents, and in particular his teacher quite by surprise.

Every time a participant attends, we select a different horse for them so they get a chance to challenge themselves with, and learn from, the reflections of different 
horses. The next horse reacted in exactly the same fashion as the first. This was not surprising really but it reaffirmed everything from his first session and enabled us to be more inquisitive about what meaning it might have to him. We also ask all participants if they have managed to take any of their new ideas about themselves home with them, and he had this great story to tell. Beaming with pride, he related to us about how things had been different in general for him at school and how in particular he had managed to achieve "a student of the week" award. This was quite unprecedented for him. The connection he made with the horse at his second session was so powerful and gave him such pleasure that when we asked how it had felt for him (as we usually do), he smiled radiantly and said, "even better than the student of the week award." We thought that was probably a very high rating for his connection and the feeling that existed between the horse and himself. He has now had his third session and has continued to progress. He is beginning to read now and do projects at home on horses. He has also approached his school principal to inform him that he considered himself ready for full-time attendance. For this third session, his father accompanied him along "to see what goes on here." He was finding it somewhat difficult to comprehend what his son was doing and the impact that it had obviously had for him. On this occasion, he worked with a horse that showed a lot of fear when it entered the yard. It was the first time this horse had worked in this particular arena and it was extremely fearful of any new situation. Once a horse feels confident in the person that it is with, it feels safe and settles and is gentle and congenial to be around. We were close by him in the yard gently advising and guiding him while he was able to demonstrate to his father how he could take this horse through a quick process of communication and projection of energy and emotions that enabled it to calm down and feel safe and visibly seek protection from him. Needless to say, his father was somewhat baffled by what he had witnessed.

For those who have not seen this process of Monty Roberts ${ }^{\circledR}$ so-called "horse whispering" in action, this may sound fanciful. But it is very real and it is possible for us to teach and assist any person to take a horse such as this through this process quickly and safely. And we never tire of being part of this journey of these people achieving these moments in their lives, particularly as the process we follow enables the journey to be significant for these young people, provided we structure it safely and with good, clear, sound therapeutic and horsepeopleship processes. The process of Join $U p{ }^{\circledR}$, if conducted well, has therapeutic value in itself; however, its value can be enhanced and it can produce so many opportunities for inquiry about stories that run counter to the stories that participants present with. It seems that our task here is to develop our skills and capacity to ensure we can identify and harness the potential new stories that are constantly coming into view through the process leading to "join up" and the events that seem to be a consequence of it. We consider we have quite a way to go yet in discovering the full potential and capacity for these young people to reposition themselves against and counter old dominant stories. We are constantly discovering new avenues to pursue and seeing 
new possibilities. Obviously not all participants respond as quickly as this young person. However his story provides a good example of the power and capacity of combining Join $U p \AA$ and Narrative Therapy practices.

We would like to indicate some of the very tentative ways we are experimenting with introducing narrative practices. Here is a line of inquiry we developed in collaboration with David for your interest.

We are imagining we are speaking to a 12-year-old young man called Johnny in proposing the following as a sequence of inquiry:

1. Johnny, do you think in general that some animals are a lot smarter than many people give them credit for? That they say horses are 'dumb' animals?

2. Johnny, has 'joining up' made you more interested in what horses and in particular what Lucky (the name of the horse he had joined up with) think?

3. Johnny, before you 'joined up' with Lucky, did you know how much horses and, in particular, Lucky are interested in us as people? What kind of people we are-scary or respectful people? People that will hurt them or break their spirits? Or people who will respect them for their 'horse-ness'? Johnny, do you think a horse can tell a person who has 'horse sense' from a person who doesn't have any 'horse sense'?

4. Johnny, do you think you learned some 'horse sense' since you first came in to the yard and you and Lucky 'joined up'?

5. Johnny, can you tell me the most interesting bit of 'horse sense' you learned buy 'joining up' with Lucky? Any other bits of 'horse sense' you've got you can think of? If not reply, ask-Do you think when you did ' $x$ ' with Lucky, that could have possibly done that with some 'horse sense'? What do you call that kind of 'horse sense'? If no reply, ask-A boy who looked a lot like you called it ' $x$ '; and a girl who thought horses were really dumb to begin with but thought very differently when she got 'horse sense' called it ' $z$ '? Does that give you any ideas for what you might call it? (If he selects one of the candidates, that's fine.)

6. Johnny, can you imagine Lucky learning some 'Johnny sense' from 'joining up' with you?

7. Johnny, do you think Lucky really had to think it over carefully if she could trust you to be her companion/leader? That you weren't out to trick her and then turn around and 'break her spirit' by being cruel to her?

8. Johnny, would you like to know more about what Lucky might be thinking about the kind of ten-year-old boy you are now that you've got 'horse sense'?

9. Johnny, can you imagine Lucky learning how to talk about how she has come to know you are her companion/leader since your 'join up'? Would you like to know more about that even if it gets told like a bed-time story?

10. Johnny, once upon a time there was a boy who looked a lot like you, with blond curly hair and blue eyes who was in trouble with a Problem (name it) who came 
to Horses For Hope here in Shepparton. Even though he had never ever come close to a real live horse before in his life (then re-tell story of his 'join up').

Here is another sample letter written with a 14-year-old girl in mind on behalf of a horse called Gus:

\section{Dear Julie:}

I met up with Gus the other day at a rodeo. You won't believe it but he obviously recognized me and came running towards me. But I am sure I saw tears in his eyes when he realized you weren't with me this time. He whinnied and you might think I am imagining things but I believe I heard people words. 'Where is Julie? Have you seen her lately? Is she as happy in her new life as I am happy in mine?' I told Gus what your foster carer, Jenny, had told me about how you were going. Now that there was less fighting, you were having a lot more fun together. You know I truly believe I saw her tears dry up. I think Gus was really cheered up by that. I believe Gus then said: 'I've got to go. I have a lot of new horse friends. Tell her thanks to her all the horses in the herd say I am a great friend! Tell her thanks to her shepherding me through some tricky and hard times in my life. I don't I could have done all this on my own!'

I know you may not believe this happened but this is how I imagined it happening.

Your friend,

David.

The task of engaging difficult to engage participants is made easier we believe by the process of demonstrating a Join Up® during the initial stages of the introduction of participants to the program. We consider this demonstration performs a number of primary functions.

It is important that prior to the Join $U p \AA$ demonstration, we provide sufficient information to create a clear context for what they are viewing and to understand what is required to enable the Join $U p{ }^{\circledR}$ to take place between horse and trainer. The stronger the demonstration of transition from fear to trust by the horse and subsequent connection between horse and trainer, the greater the intrigue and interest in the process. A very typical response is: "Wow, could I do that?" Most who watch their first demonstration find it emotionally powerful and extremely intriguing and are interested to try it for themselves. After all, many of our horses outweight their trainers by a very considerabvle margin.

We believe that a significant level of engagement and trust is thereby established between those watching and sensing a horse make a transition from fear to trust and the Horses For Hope team member who is doing the demonstration. We suspect there is a sense of "if the horse can trust that person and this team, perhaps I can as well." This combined with the intrigue allows participants to take the often daunting step to get into the horse yard and attempt this complex and difficult task. We call this "the Pied Piper effect." When the new participant trusts us sufficiently to step into the horse yard with us and achieve a Join Up® (we ensure they all do achieve that), their sense of achievement is great and the connection with the program team 
is enhanced. At this point, the trust they have given us has been tested and we have been found to be worthy of it. At this stage, the program connections are off and running and the therapeutic potential is enhanced greatly.

There is a standard process for all sessions regardless of age of participant or type of problems that the participant is experiencing. A standard session for an individual is one hour; however a first session exceeds that by a half hour. Each session includes a session with a horse followed up by a conversation. Each session is usually a three stage process as follows:

(i) A short review of events that have happened since the last session, things that they have noticed about themselves, how it has gone in being able or unable to take their horse sense and people sense home with them, have they been able to keep their horse memory with them and has the horse memory been able to help guide them through some hard and tricky situations.

(ii) Assisted Join Up® experience with a horse. We aim to have a different horse for each session, as each horse brings with it different experiences and different needs. This enables participants to be challenged and to practice different skills and often confront different concerns. Throughout this session with the horse, we encourage participants to reflect on what meaning they have drawn from the experience and what learning is taking place for them at that time.

(iii) Follow-up conversation seeking to review the experience of the day, to draw any special meaning from the experience and to discuss taking any new knowledge and expectations home with them.

Throughout this process we aim to model respect, Shepherd leadership, calmness, trust, and respect and we are always interested and inquisitive.

A first session also needs to include a component of teaching about horses and horse psychology and the communication techniques that we use to Join Up® with a horse. In the follow up sessions there is always an educational component, as participants develop their level of knowledge and skills of "horse sense."

It is not possible to undertake this process of Join $\mathrm{Up}^{\circledR}$ with a horse without considering notions of leadership, because in effect the person must be able to establish a position of herd leadership for the horse they are working with. This must be based on trust, respect, calm, and leadership that we describe as Shepherd leadership (eg., developing the capacity to shepherd horses through hard and tricky situations as opposed to coercing, forcing, or making a horse accept our leadership). We are seeking the establishment of a willing partnership between the participant and the horse. Traditional horse education and training has commonly been referred to as horse breaking which is undertaken by means of coercion, brute force, and often frank violence. In essence this describes the process of breaking a horse's spirit in where there is no sense of partnership and collaboration. By contrast, the process we employ, which is commonly referred to as "horse whispering," is actually about listening and the capacity to look at 
oneself "through the eyes of the horse." While it is primarily about the establishment of a partnership, the person in the partnership must be the leader, and we believe this needs to be in the style of a Shepherd leader. It is not possible to establish this kind of partnership when any sense of aggression, coercion, or violence exists within the relationship. Participants see and feel this played out very strongly with the horses and there is a lot that can be drawn for person to person relationships from this. It is a very vivid opportunity to consider different types of relationships and to see the benefits of relationships established on the basis of trust, respect, calm, and what we refer to as Shepherd leadership.

Interestingly we see that this idea of leadership can be mapped on to other relationships (eg., Age mates, children-parents, students-teachers, etc.). Such mappings seem to enable them to consider from different perspectives the roles, responsibilities, and the meeting of children and young people's needs for care and protection and the need for parents and teachers etc. to provide this. We find that they see these needs played out in the horse yard as the horses respond to feeling safe and secure within the strong, calm, respectful Shepherd leadership that the participants learn to provide. We believe these ideas are helpful in revising family relationships, in particular those that have become very strained.

The process is also a very real opportunity for participants to view and practice techniques of finding, promoting, and projecting calm which might not be in their repertoire. Likewise, it is an opportunity to practice projecting strength without aggression. There is an expectation that participants will use and practice this within the horse yard and elsewhere because the task of establishing a partnership based on Shepherd leadership requires the presentation of both strength without aggression, genuine calm, and trust and respect in order for the horse to accept the person as the Shepherd leader. It is a very powerful moment when the horse says to the participant through its actions, "I give myself to you for your protection. Please look after and protect me and keep me safe. I no longer need to be concerned about the world because you will watch out for me. I can relax now. Thank you."

We are constantly encouraged by the outcomes that are being achieved by participants in the program and continually seek to improve our practices and our own skills to ensure we maximize potential outcomes for participants.

Common feedback from the referring professionals is that they are impressed and surprised by the level of engagement of the participants and the speed at which participants are able to contest the Problems that were often very entrenched. Most often participants enjoy the experience of working with horses in this way and consequently often find enthusiasm for confronting problems that they have hitherto felt incapable of confronting. The overriding expression that we get from participants is joy and pleasure at participating in the program and surprise at what they are able to achieve with both the horses and themselves. It is a very great pleasure and privilege to be able to share these journeys. Every day we are constantly surprised and delighted for and by our horses and participants.

It might be worth saying a few words about the horses in the program. In general, we do not own the horses; they are lent to us for the explicit purpose of their owners 
seeking our assistance with their "horse" problems. Some will remain in the program for longer periods; others will stay for short periods while their view of humans as predators is changed by the young people who participate in the program. As a consequence, we have a constant movement of horses through the program and while this is an essential element of the program's success (ie. having horses that need "unsuffering") it is time-consuming for our team to locate and ensure that the horses are suitable (eg. they will not endanger our young participants). As our reputation has been established in the area, horses are now being regularly offered to us for participation in the program by owners who have heard of the potential benefits for their horses as well as their relationships with them.

In our bushfire recovery component of the program, people often attend with their own horses, most of whom have survived the fires as well and have been traumatized by those events. In these instances, we have traumatized people owning and trying to cope with and help traumatized horses. These people work with us for the purpose of "unsuffering" the horses and themselves. This too is often a very powerful process for both.

Currently, the program is not directly funded by government sources although the bushfire recovery part of the program has been funded through a fund established from donations immediately after the fires. The general program runs on the basis of feefor-service with referrers such as government departments and schools often funding participants' attendance. The fee charged is usually not full cost recovery and the auspice agency of the program, UnitingCare-Cutting Edge, uses fundraising to subsidize the program cost, in order to keep the fee-for-service level down to a rate that referring agencies and government departments can afford. The same applies for paying families who refer themselves. The program works with both individuals and groups but with the latter, we aim to keep the maximal numbers for groups to four participants in order to provide the level of personalized input required for impact to be achieved.

\section{ACKNOWLEDGEMENTS}

I wish to acknowledge the influence and inspiration of Monty Roberts ${ }^{\circledR}$, David Epston, and the late Michael White. My colleague in developing and providing Horses for Hope, Tiffany Peverall, trains with Monty and late in 2011 will become a fully accredited instructor. Alison Pozzobon is a talented young horsewoman who joined our team as an assistant 12 months ago. Daryl Nioa is a volunteer who gives an enormous amount of time to the program and is a wonderful support and helper. Angela O'Conner, a youth worker colleague at UnitingCare-Cutting Edge with an interest and skills in family therapy who has been a great help in assisting me with the development and delivery of the therapeutic components of the program. It would be most remiss of me if I did not also acknowledge the support and guidance of the Board and Management of the agency UnitingCare-Cutting Edge. Without their faith in the program, support, resources, and encouragement, Horses for Hope would never have been able to develop successfully in the manner 
it has. And to the many wonderful participants, all of whom add so much to our lives and each and every one contributes to the stock of knowledge that combines to create Horses For Hope.

Colin Emonson can be contacted at colin@ucce.org.au.

\section{REFERENCES}

Roberts, M. (2002). Horse Sense for People, New York; Penguin.

Roberts, M. (2008). The Man Who Listens to Horses: The Story of the Real-Life Horse Whisperer, New York; Ballantine. 
Copyright of Journal of Systemic Therapies is the property of Guilford Publications Inc. and its content may not be copied or emailed to multiple sites or posted to a listserv without the copyright holder's express written permission. However, users may print, download, or email articles for individual use. 